\title{
Micropropagation of Genista aetnensis [(Raf. ex Biv.)DC]
}

\author{
Giovanni IAPICHINO ${ }^{1 *}$, Marcello AIRÒ ${ }^{2}$,Emilio LO PRESTI ${ }^{1}$, Leo SABATINO ${ }^{1}$ \\ ${ }^{1}$ Università degli Studi di Palermo, Dipartimento di Scienze Agrarie e Forestali, Viale delle Scienze, 90128, Palermo, Italy; \\ giovanni.iapichino@unipa.it(*correspondingauthor);emilio.lopresti@gmail.com;leo.sabatino@unipa.it \\ ${ }^{2}$ CREA-Consiglio per la Ricerca in Agricoltura el'Analisi dell'Economia Agraria. Unità di Ricerca per il Recupero ela Valorizzazione \\ delleSpecie Floricole Mediterranee(SFM),Bagheria(PA),Italy;marcello.airo@entecra.it
}

\begin{abstract}
Genista aetnensis [(Raf. ex Biv.)DC] is a large deciduous shrub or small tree native to the Italian islands of Sardinia and Sicily. Being winter hardy and characterized by high plasticity in altitude and ecology, the species is grown in gardens and landscaping, both for flower and for its attractive shape. Genista species are generally propagate by seed or semi-hardwood cuttings. In this report an efficient in vitro technique for propagation of $G$. aetnensis was investigated. Multiple shoots were induced on nodal segments of a mature plant of Genista aetnensis. The Murashige and Skoog medium, augmented with different concentrations of $\mathrm{N}^{-6}$-benzyladenine either singly or in combination with indole-3-acetic acid, as potential medium for shoot multiplication by nodal segments was tested. In the following experiment equal molar concentrations of four cytokinins (2-isopenthenyladenine, kinetin, zeatin and $\mathrm{N}^{-6}$-benzyladenine) were tested for ability to induce axillary shoot development from single node stem segments. The highest rate of axillary shoot proliferation was induced on the medium supplemented with $0.44 \mu \mathrm{M}$ BA. Growth regulator requirements for shoot proliferation in $G$. aetnensis were satisfied by BA alone. Explants were divided, subcultured and continued to proliferate shoots. A proliferation rate of 3.5 shoots per single node explants every four weeks occurred. Seven indole-3-acetic acid concentrations $(0,0.23,0.45,0.91,1.82,3.64$ or $7.29 \mu \mathrm{M})$ were tested to determine the optimum conditions for in vitro rooting of microshoots. The highest rooting percentage was obtained with indole-3-acetic acid at $3.64 \mu \mathrm{M}(57 \%)$. Eighty percent of the in vitro rooted plantlets were successfully established in soil. This micropropagation system of $G$. aetnensis based on axillary shoot development from nodal segments followed by in vitro rooting should be preferred for rapid and efficient mass propagation of selected clones and could represent an alternative method to sexual and conventional asexual propagation.
\end{abstract}

Keywords: in vitro rooting, growth regulators, Mount Etna broom, node culture, shoot multiplication

\section{Introduction}

The genus Genista (family Fabaceae) comprises approximately 100 species distributed over Asia, Northern Africa, Europe and the Mediterranean basin (Bisby, 1981). About forty entities, including species and subspecies, are present in Italy and Tyrrhenian islands (La Mantia, 2009). Genista aetnensis [(Raf. ex Biv.)DC] (here after called Genista aetnensis), commonly known as Mount Etna broom is a large deciduous shrub or small tree native to the islands of Sardinia and Sicily on dry hills at up to $2000 \mathrm{~m}$ (Pignatti, 2003). Endemic to the lavastrewn slopes of Sicily's Mt. Etna, the species produces slender, arching green shoots, small, sparse leaves and bright yellow, fragrant, pea-shaped flowers, from middle to late summer (Brickell and Cathey, 2008). Sometimes grown in gardens and landscaping, both for flower and for its attractive shape when mature, the plant has been also reported to arrest erosion and induce pedogenesis on Entisols at different altitude on Mount
Etna (Fernandez Sanjurjo et al., 2003). Being winter hardy ( -15 ${ }^{\circ} \mathrm{C}$ ) and characterized by high plasticity in altitude and ecology, ranging from 100 to $2000 \mathrm{~m}, G$. aetnensis was introduced into cultivation in Britain in 1823 and is popular in gardens, especially in South England (Brickell and Cathey, 2008). Genista species are propagate by seed or semi-hardwood cuttings (Hartmann et al., 2003; Dirr and Heuser, 2006). However, considered the high degree of heterozygosity of Genista (Curir, 1986) micropropagation could be an alternative and effective method for rapid mass propagation of selected clones of $G$. aetnensis. Euczkiewicz and Piotrowski (2005) in the attempt to achieve production of secondary metabolites by in vitro culture, report the micropropagation of six Genista species, including $G$. aetnensis. However, in that article only the data referring to $G$. tinctoria shoot proliferation and rooting were presented, whereas no specific information regarding the growth regulators requirements for stimulating shoot proliferation and rooting of

Received: 21 July 2015. Received in revised form: 24 Nov 2015. Accepted: 26 Nov 2015. Published online: 10 Dec 2015. 
G. aetnensis were provided. Furthermore, those authors used seeds as primary explants material to establish Genista shoot culture. Because species belonging to Genista genus are outcrossers, propagation by seed does not guarantee that the characteristics of a particular selected genotype will be maintained. On the other hand, since in the ornamental tree culture, asexual propagation is needed to maintain the characteristics of a selected genotype, a micropropagation system of $G$. aetnensis based on axillary buds and nodal segments as primary explants should be preferred.

Several studies have showed evidence of synergistic effect of cytokinins and auxins in axillary shoot proliferation of shrubs and trees (Ruffoni et al., 1994; Yeo and Reed, 1995; Ma et al., 1996; Mokotedi et al., 2003). For example, stimulatory effects of low auxin concentrations and inhibitory effects of high auxin concentrations have been reported by Yeo and Reed (1995) in Pyrus spp. Since our preliminary experiments (Iapichino, unpublished) showed that either IBA or NAA in combination with different cytokinins induced only callus formation in $G$. aetnensis in vitro shoot culture, we decided to focus our study on the potential synergistic effects of IAA and BA on axillary shoot proliferation. Following this experiment, various cytokinins were also tested for shoot multiplication. As in vitro rooting is concerned, a preliminary study (Iapichino, unpublished) indicated that exposing $G$. aetnensis axillary shoots to the presence of either IBA or NAA resulted only in callus growth and no root formation, therefore in the present experiment we decided to choose IAA as potential auxin to induce in vitro rooting. Thus, the objective of the present study was to develop an efficient protocol of micropropagation of $G$. aetnensis.

\section{Materials and Methods}

\section{Culture establishment}

Plant material was harvested in May 2013 from a wild plant growing at the base of Mount Etna, Sicily (Italy). The plant was selected because of its foliage mass and vigor. Actively growing apical shoot tips, $8-10 \mathrm{~cm}$ in length and 2-3 $\mathrm{mm}$ in diameter, and bearing 78 nodes, were cut and used as the starting material. After removing the apices, explants were rinsed under running tap water for 10-12 min and then surface-disinfested with a 15-sec immersion in 70\% ethanol followed by continuous, gentle agitation for $20 \mathrm{~min}$ in a bleach solution $[1.05 \% \mathrm{NaOCl}(\mathrm{w} / \mathrm{v})]$ containing 20 drops/liter of Tween 20 (Sigma Chemical Co., St. Louis, MO) and three 10-min rinses in sterile distilled water. The basal and the apical ends were aseptically removed and explants sectioned in stem segments bearing two or three nodes. Individual stem segments were placed horizontally into each sterilized $90 \times 15 \mathrm{~mm}$ Petri dishes containing $25 \mathrm{ml}$ of Murashige and Skoog(MS) (Murashige and Skoog, 1962) basal medium (Sigma no. M-5524) (plus $20 \mathrm{gl}^{1-1}$ sucrose, $8.0 \mathrm{gl}^{-1}$ Agar (Sigma no. A-1296) and $0.22 \mu \mathrm{M}$ of $\mathrm{N}^{6}$-benzyladenine (BA) (Sigma no. B-9395) to induce axillary shoot development. All media described also later were adjusted to $\mathrm{pH} 5.7$ with $\mathrm{NaOH}$, and autoclaved at $121^{\circ} \mathrm{C}$ at $103 \mathrm{kpa}$ for $20 \mathrm{~min}$. After 5 weeks of culture,

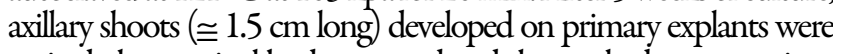
excised, the terminal buds removed and the resulted stems cut into segments, bearing two or three nodes. Nodal segments were subcultured into each sterilized glass culture vessel (height $95 \mathrm{~mm}$, width $50 \mathrm{~mm}$ ) containing $30 \mathrm{ml}$ of the same medium 5 more times at 4 week intervals to increase the stock of shoot cultures. Shoots were then subcultured on the same MS medium without growth regulators for 3 weeks before being used either in multiplication treatments or in the rooting treatment. All cultures were maintained at $25^{\circ} \mathrm{C}$ under a 16 -h photoperiod provided by coolwhite fluorescent tubes, $35 \mu \mathrm{mol} \cdot \mathrm{m}^{-2} \cdot \mathrm{s}^{-1}$. The same conditions were used for all experiments.

\section{Multiplication of axillary shoots}

Randomly selected axillary shoots were cut from established cultures, the terminal buds removed and the resulted stems cut into segments. Nodal explants (segments comprising an axillary bud and a 5-10-mm internodal stem below the node) were transferred to in vitro multiplication treatments. In both experiments the medium was the same as described earlier. The sterilized media were dispensed into each sterilized glass culture vessel (height $95 \mathrm{~mm}$, width $50 \mathrm{~mm}, 30 \mathrm{ml}$ medium per vessel). In the first experiment, BA concentrations of $0,0.44,0.88$ or $1.32 \mu \mathrm{M}$ in combination with indole-3-acetic acid (IAA) (Sigma no. I2886) concentrations of 0 and $0.57 \mu \mathrm{M}$, were tested in a twofactor, randomized, complete design. Each treatment consisted of five replicates. Each replicate consisted of a glass culture vessel containing five explants (total 25 explants). In a further experiment, the optimal concentration of BA $(0.44 \mu \mathrm{M})$ for inducing axillary shoot proliferation was tested in a randomized, complete design against equal molar concentrations of different cytokinins [2-isopenthenyladenine (2iP) (Sigma no. D-4542), kinetin (Sigma no. K-0753), zeatin (Sigma no. Z-0876) and BA]. Each treatment consisted of five replicates. Each replicate consisted of a glass culture vessel containing five explants (total 25 explants). Growth regulators were added to the media prior to autoclaving, except when different cytokinins were compared, growth regulators were filter-sterilized $(0.45 \mu \mathrm{m}$, Nalgene $)$ and added after the media were autoclaved and cooled to about $50{ }^{\circ} \mathrm{C}$. Stem segments were vertically placed into culture. For all multiplication treatments, nondestructive observations were performed after 4 weeks of culture and shoot proliferation scores were based on the number of usable shoots ( $\geq 10 \mathrm{~mm}$ long). In both experiments, Fisher's protected least-significant-difference test at $(\mathrm{p} \leq 0.01)$ was used to separate the means for significant effects from the analysis of variance (Petersen, 1985).

\section{In vitro rooting}

Randomly selected individual shoots $\cong 2.0 \mathrm{~cm}$ long with intact apex were trimmed of basal leaves and subjected to in vitro rooting media. To determine the optimum conditions for in vitro rooting, media containing $1 / 2 \mathrm{MS}$ salts and vitamins, plus $20 \mathrm{gl}^{-1}$ sucrose, 8.0 $\mathrm{g} \mathrm{l}^{-1}$ agar (Sigma no. A-1296) were dispensed into sterilized glass culture vessel $(30 \mathrm{ml}$ medium per vessel). Seven IAA concentrations $(0,0.23,0.45,0.91,1.82,3.64$ and $7.29 \mu \mathrm{M})$ were investigated in a completely randomized design. Each treatment consisted of five replicates as described for multiplication axillary shoot experiments.

After 6 weeks, data were recorded as percentage of shoots rooted, mean number of roots per shoot and mean root length. Percentage data were subjected to arcsin transformation before ANOVA analysis. Mean separation was performed by Fisher's protected least-significant difference test $(\mathrm{p} \leq 0.01)$ (Petersen 1985).

\section{Plant greenhouse establishment}

In vitro rooted plantlets were removed from culture media 
Table 1. Effects of different concentrations of IAA and BA on in vitro axillary shoot proliferation of Genista aetnensis

\begin{tabular}{|c|c|c|c|c|}
\hline \multicolumn{2}{|c|}{ Growth regulators $(\mu \mathrm{M})$} & \multirow{2}{*}{$\begin{array}{l}\text { Shoots per explant } \\
\text { (number) }\end{array}$} & \multirow{2}{*}{\multicolumn{2}{|c|}{$\begin{array}{l}\text { Shoot length } \\
(\mathrm{mm})\end{array}$}} \\
\hline IAA & $\mathrm{BA}$ & & & \\
\hline 0 & 0 & $0.8 \pm 0.1 \mathrm{e}$ & 34 & $\pm 2.6 \mathrm{a}$ \\
\hline 0 & 0.44 & $3.5 \pm 0.7 \mathrm{a}$ & 25 & $\pm 2.1 \mathrm{c}$ \\
\hline 0 & 0.88 & $2.0 \pm 0.5 b$ & 20 & $\pm 0.7 \mathrm{~d}$ \\
\hline 0 & 1.32 & $1.9 \pm 0.3 \mathrm{bc}$ & 13 & $\pm 0.7 \mathrm{e}$ \\
\hline 0.57 & 0 & $0.4 \pm 0.1 \mathrm{e}$ & 15 & $\pm 0.5 \mathrm{e}$ \\
\hline 0.57 & 0.44 & $1.5 \pm 0.1 \mathrm{~cd}$ & 30 & $\pm 1.7 \mathrm{ab}$ \\
\hline 0.57 & 0.88 & $1.7 \pm 0.6 \mathrm{bcd}$ & 26 & $\pm 2.0 \mathrm{c}$ \\
\hline 0.57 & 1.32 & $1.8 \pm 0.4 \mathrm{bcd}$ & 14 & $\pm 0.6 \mathrm{e}$ \\
\hline
\end{tabular}

Table 2. Effects of different cytokinins on in vitro axillary shoot proliferation of Genista aetnensis after fourweek culture

\begin{tabular}{ccc}
\hline $\begin{array}{c}\text { Cytokinins } \\
(0.44 \mu \mathrm{M})\end{array}$ & $\begin{array}{c}\text { Shoots per explant } \\
\text { (number) }\end{array}$ & $\begin{array}{c}\text { Shoot length } \\
(\mathrm{mm})\end{array}$ \\
\hline $2 \mathrm{iP}$ & $0.4 \pm 0.1 \mathrm{c}$ & $31 \pm 1.1 \mathrm{a}$ \\
Zeatin & $1.0 \pm 0.2 \mathrm{~b}$ & $30 \pm 1.7 \mathrm{a}$ \\
BA & $3.6 \pm 0.4 \mathrm{a}$ & $23 \pm 1.3 \mathrm{~b}$ \\
Kinetin & $0.3 \pm 0.1 \mathrm{c}$ & $26 \pm 1.4 \mathrm{ab}$ \\
\hline
\end{tabular}

Values represent mean \pm standard error. In each column, means followed by the same letters are not significantly different at the $\mathrm{p}<0.01$ level by Fisher's protected least significant difference test.

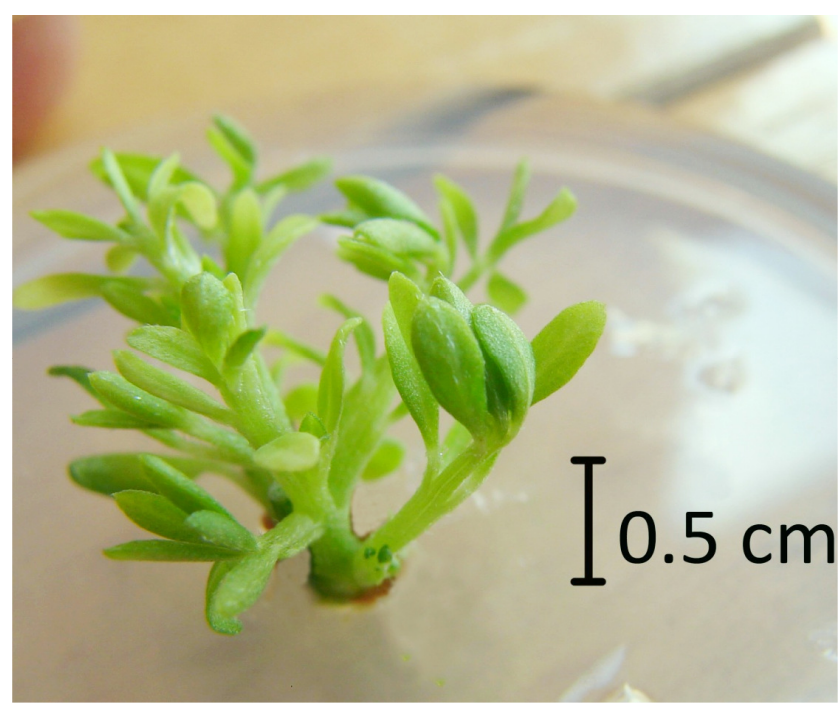

Fig. 1. Cluster of axillary shoots proliferated from single-node stem segment of Genista aetnensis cultured in MS medium supplemented with $0.44 \mu \mathrm{MBA}$

and agar was gently washed from the roots. Plantlets were transplanted into trays containing a peat-perlite mixture 1:1 (v/v) covered with clear plastic bags to maintain a high relative humidity. The growing mixture was kept moist by frequent watering and trays were kept in a wood-made cold frame covered with a 70\% polypropylene shade-cloth (lath-house). Ventilation of the plantlets was increased with time by increasing size of the holes made in the plastic, and after 3 weeks the plastic was removed. After 5 weeks, acclimatized single plants were transferred to each plastic pot containing the same growing mixture.

\section{Results and Discussion}

\section{Culture establishment}

About $60 \%$ of the axillary shoots developed from the primary explants appeared free of fungal or bacterial contamination after applying the disinfection procedures described in this study. Axillary buds started to grow after two weeks in culture in medium with 0.22 $\mu \mathrm{M}$ BA and were about $20 \mathrm{~mm}$ tall after four weeks. Nodal segments subcultured onto the same medium continued to develop new axillary shoots. Transferring single shoots into the same medium without growth regulators resulted in main shoot growth, whereas further axillary shoot proliferation did not occur. As it is well known, nodes are reliable explants to be used to propagate in vitro several woody dicotyledons (George, 1996).

\section{Multiplication of axillary shoots}

Shoot proliferation occurred through development of existing axillary buds. The effects of IAA and BA concentrations on axillary shoot proliferation from nodal explants after four week culture are shown in Table 1 . The IAA concentration $\mathrm{x}$ BA concentration interaction was significant. Shoot number per explant ranged from $0.4 \pm 0.1$ in the medium containing only $0.57 \mu \mathrm{M}$ IAA to an optimum of $3.5 \pm 0.7$ in the medium supplemented with only 0.44 $\mu \mathrm{MBA}$ (Fig. 1).

In our experiment, the presence of the auxin IAA in the medium reduced axillary shoot proliferation. In fact, at all BA levels, shoot multiplication was lower with IAA concentration of $0.57 \mu \mathrm{M}$ than at $0 \mu \mathrm{M}$. Shoot number also declined when node explants were exposed to BA concentrations above $0.44 \mu \mathrm{M}$ BA, either in the presence or absence of IAA.

Our findings are similar to those obtained by Łuczkiewicz and Piotrowski (2005) who found IAA interfering with shoot proliferation in Genista tinctoria. Our results are also consistent with those of Romano et al. (2002) who found that the combination of BA and IAA did not improve the multiplication rate of Ceratonia siliqua, another member of the Fabaceae.

The best result in terms of shoot length was obtained from the medium without growth regulators $(34 \pm 2.6 \mathrm{~mm})$ followed by the medium with $0.57 \mu \mathrm{M}$ IAA and $0.44 \mu \mathrm{M}$ BA. Exposure of node explants to 0 IAA $\mu \mathrm{M}+0.44 \mu \mathrm{M}$ BA and $0.57 \mathrm{IAA}+0.88 \mathrm{BA}$ resulted in axillary shoots which attained $25 \pm 2.1$ and $26 \pm 2.0 \mathrm{~mm}$ length, respectively. Exposure of node explants to $1.32 \mu \mathrm{MBA}$ either in the presence or absence of IAA significantly reduced shoot length compared to media with lower BA concentrations. The concentration of $0.44 \mu \mathrm{MBA}$ which produced favourable results in terms of axillary shoot number was used in equal molar comparisons with other cytokinins (zeatin, 2iP, and kinetin). Among the cytokinins tested (Table 2), BA gave the highest proliferation rate (3.6 \pm 0.4 shoots per explant) followed by zeatin ( $1.0 \pm 0.2$ shoots per explant), whereas $2 \mathrm{iP}$ and kinetin resulted in the poorest scores ( $0.4 \pm 0.1$ and $0.3 \pm 0.1$ shoots per explants, respectively).

Benzyladenine has been found to be more effective than other cytokinins at stimulating axillary shoot development in Acacia mearnsii, another member of the Fabaceae family (Feng et al., 1994). Shoots proliferated in the medium supplemented with BA although were significantly shorter than those produced from node explants exposed to $2 \mathrm{iP}$ and zeatin, attained growth sufficient $(23 \pm 1.3 \mathrm{~mm})$ for the transfer to root induction medium. The best treatment of this experiment was repeated in 2014 with new plant material from the same stock and obtaining similar results. 
In vitro rooting and plant greenhouse establishment

In vitro rooting of excised shoots was accomplished in about five weeks (Fig. 2).Effect of IAA concentration on rooting of $G$. aetnensis microshoots, after 5 weeks in culture, is presented in Table 3.

Table 3. Effects of IAA concentrations on in vitro rooting of Genista aetnensis axillary shoots after 5 weeks culture

\begin{tabular}{ccclc}
\hline $\begin{array}{c}\text { IAA } \\
(\mu \mathrm{M})\end{array}$ & $\begin{array}{c}\text { Rooting } \\
(\%)\end{array}$ & $\begin{array}{c}\text { Roots/shoot } \\
(\text { number })\end{array}$ & $\begin{array}{c}\text { Root length } \\
(\mathrm{mm})\end{array}$ \\
\hline 0 & $10.0 \pm 0.3 \mathrm{e}$ & $2.2 \pm 0.3 \mathrm{bc}$ & $4.2 \pm 0.4 \mathrm{de}$ \\
0.23 & $13.1 \pm 0.7 \mathrm{de}$ & $1.1 \pm 0.2 \mathrm{e}$ & $7.8 \pm 0.1 \mathrm{a}$ \\
0.45 & $31.0 \pm 3.1 \mathrm{~b}$ & $1.5 \pm 0.2 \mathrm{de}$ & $6.9 \pm 0.6 \mathrm{~b}$ \\
0.91 & $27.0 \pm 2.0 \mathrm{bc}$ & $1.4 \pm 0.5 \mathrm{e}$ & $5.4 \pm 0.2 \mathrm{~cd}$ \\
1.82 & $53.0 \pm 5.4 \mathrm{a}$ & $2.0 \pm 0.3 \mathrm{~cd}$ & $6.0 \pm 0.8 \mathrm{c}$ \\
3.64 & 57.0 & $\pm 4.8 \mathrm{a}$ & $3.5 \pm 0.8 \mathrm{a}$ & $3.6 \pm 0.4 \mathrm{e}$ \\
7.29 & $23.7 \pm 3.0 \mathrm{bcd}$ & $2.6 \pm 0.4 \mathrm{~b}$ & $3.6 \pm 0.7 \mathrm{e}$ \\
\hline
\end{tabular}

Values represent mean \pm standard error. In each column, means followed by th same letters are not significantly different at the $p \leq 0.01$ level by Fisher's protected least-significant-difference test.

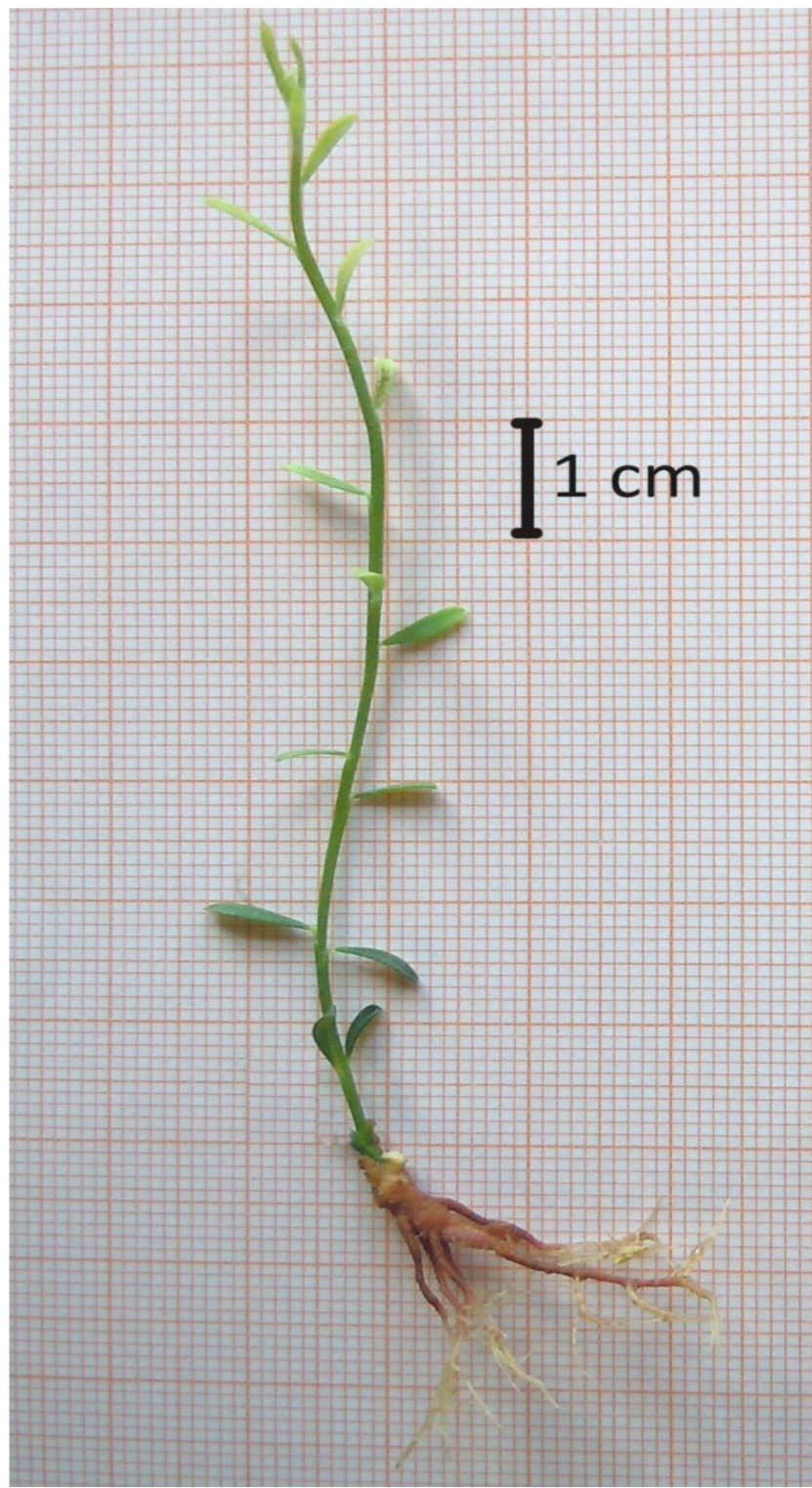

Fig. 2. Plantlet of Genista aetnensis with in vitro-regenerated root system in the presence of $3.64 \mu \mathrm{M}$ IAA

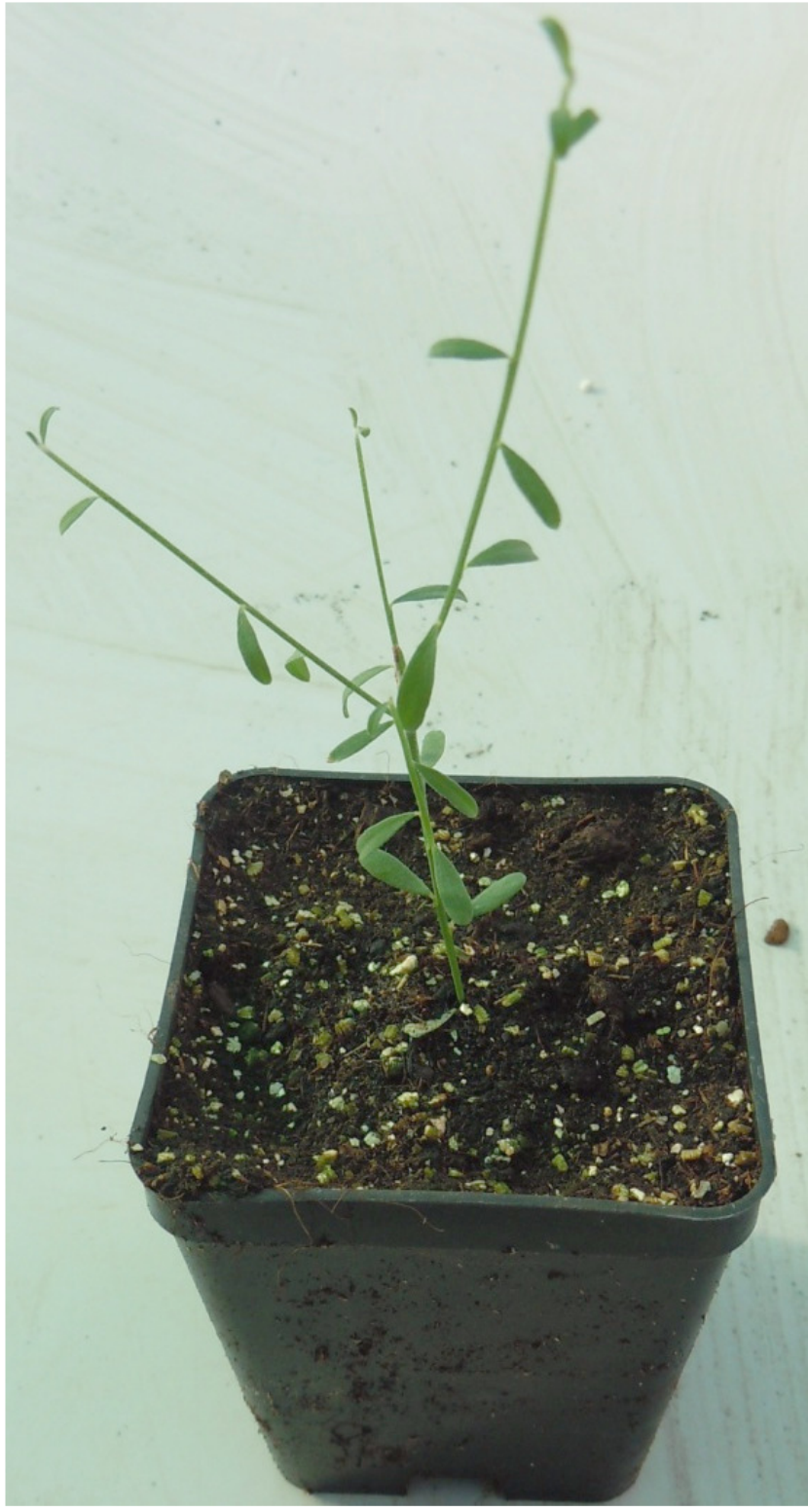

Fig. 3. Genista aetnensis acclimatized plant

Rooting in absence of growth regulator resulted in only $10 \%$ success. The highest rooting percentages were obtained with IAA at 1.82 and $3.64 \mu \mathrm{M}$ (53 and 57\%, respectively). Exposing microshoots to IAA at $7.29 \mu \mathrm{M}$ substantially reduced rooting performance $(23.7 \%$ rooting). Absence of IAA resulted in plantlets with 2 roots. The treatment that produced the most roots was obtained with IAA at $3.64 \mu \mathrm{M}(3.5 \pm 0.8$ roots per shoot). Root number decreased at IAA levels higher and lower than $3.64 \mu \mathrm{M}$. Our results show that although rooting percentage in the presence of 3.64 IAA $\mu \mathrm{M}(57 \%)$ was not significantly different from the one obtained with 1.82 IAA (53\%), doubling IAA concentration resulted in a significantly higher number of roots per shoot. As root length is concerned, treatments that produced the longest roots were obtained with $0.23 \mu \mathrm{M}$ IAA $(7.8 \pm 0.1 \mathrm{~cm})$ followed by IAA at $0.45 \mu \mathrm{M}(6.9 \pm 0.6 \mathrm{~cm})$. Root length with the absence of growth regulator or with IAA concentrations higher than $1.82 \mu \mathrm{M}$ was significantly inferior compared to the other treatments. Therefore, the best treatment for rooting was $3.64 \mu \mathrm{M}$ IAA. Eighty percent of the in vitro rooted 
546

plantlets transferred to soil (Fig. 3) survived regardless of the medium tested to induce rooting. A total of 50 plants were established in the lath-house.

\section{Conclusion}

This paper reports a successful micropropagation protocol of G. aetnensis through nodal explants from mature plants. Node culture has been previously adopted to propagate in vitro shrubs and trees (George, 1996; Suttle, 1999). This method is considered convenient and reliable because using pre-existing bud explants it is least likely to induce genetic mutation (Chu, 1992), and therefore it is a preferred system for commercial micropropagation (Suttle, 1999). The highest rate of axillary shoot proliferation was induced on MS medium augmented with $0.44 \mu \mathrm{M}$ BA. Explants were divided, subcultured and continued to proliferate shoots. A proliferation rate of 3.5 shoots per single node explants every four weeks occurred. Our results are in accord with that obtained by Curir et al. (1986) who, investigating the axillary shoot proliferation response of five clones of Genista monosperma cultured on MS medium with the addition of BA, found a multiplication rate ranging from 2 to 6 . Our findings also suggest that growth regulator requirements for shoot proliferation in $G$. aetnensis can be satisfied by BA alone. In addition, we demonstrated the superiority of BA over the other cytokinins tested in inducing the development of axillary shoots in vitro. Our results are only partially in agreement with those obtained by Euczkiewicz and Piotrowski (2005) who found BA superior to zeatin and kinetin, but less effective than $2 \mathrm{iP}$ in promoting axillary shoot proliferation in G. tinctoria. The different response found in our experiment could be related to the diverse species studied. Up to $57 \%$ of the microshoots rooted in the medium containing $1 / 2$ MS salts and 3.64 $\mu \mathrm{M}$ IAA. This result is consistent with that of Curir et al. (1986) who found IAA being effective in stimulating adventitious root formation in $G$. monosperma. Our preliminary unsuccessful rooting results with IBA and NAA might be related to the fact that during the adventitious root induction phase a high auxin concentration is generally required, whereas during the root formation phase growth regulators become inhibitory. Therefore, we may speculate that higher stability and consequent supraoptimal concentrations of NAA and IBA might induce callus growth and inhibit root formation in G. aetnensis as opposed to IAA which being unstable and easily degradable in the presence of light, would on the contrary favor root growth and elongation.

The in vitro rooting and acclimatization process took approximately 14 weeks. Micropropagated plants are under evaluation for their clonal fidelity and agronomic behavior. However, further studies are required to improve in vitro rooting efficiency and/or evaluate the possibility to establish a more efficient system based on ex vitro rooting of $G$. aetnensis microcuttings.

\section{References}

Bisby FA (1981). Genisteae. In: Polhill RM, Raven PH (Eds). Advances in legume systematics, Part 1. Royal Botanic Gardens, Kew, UK pp 409-425.

Brickell C, Cathey HM (2008). RHS A-Z Encyclopedia of Garden Plants. Dolring Kindersley Limited, London.
Chu IYE (1992). Perspective of micropropagation industry. In: Kurata K, Kozay T (Eds). Transplant production systems. Kluwer Academic Publishers, Amsterdam pp 137-150.

Curir P, Damiano C, Cosmi T (1986). In vitro propagation of Genista monosperma. HortScience 21:859.

Dirr MA, Heuser CW (2006). The reference manual of woody plant propagation. Varsity Press, Athens.

Feng HH, Al-Khayri JM, Gbur EE (1994). Micropropagation of Acacia mearnsii. In Vitro Cellular and Developmental Biology-Plant 30:70-74.

Fernandez Sanjurjo MJ, Corti G, Certini G, Ugolini FC (2003). Pedogenesis induced by Genista aetnensis (Biv.) DC. on basaltic pyroclastic deposits at different altitudes, Mt. Etna, Italy. Geoderma 115:223-243.

Hartmann HD, Kester DE, Davies FJ, Geneve RL (2003). Plant Propagation: Principles and Practices. Prentice Hall, New Jersey.

George EF (1996). Plant propagation by tissue culture - Part 1: the technology. Exegetics Ltd Edington, Wilts.

La Mantia A, Aprile S, Sortino M, Zizzo GV (2009). Investigations on some Sicilian autochthonous brooms and their potentialities in the floricultural sector. Acta Horticulturae 813:45-53.

Łuczkiewicz M, Piotrowski A (2005). Two-stage system for micropropagation of several Genista plants producing large amounts of phytoestrogens. Z Naturforsch 60:557-566.

Ma Y, Byrne, DH, Chen J (1996). Propagation of rose species in vitro. In Vitro Cellular and Developmental Biology-Plant 32:103108.

Mokotedi OME, Watt MP, Pammenter NW, Blakeway FC (2003). In vitro rooting and subsequent survival of two clones of a cold-tolerant Eucaliptus grandis X E. nitens hybrid. HortScience 35:1163-1165.

Murashige T, Skoog F (1962). A revised medium for rapid growth and bioassays with tobacco tissue cultures. Physiologia Plantarum 15:473-497.

Petersen RG (1985). Design and analysis of experiments. Marcell Dekker, New York.

Pignatti S (2003). Flora d'Italia. Vol I. Edagricole, Bologna, Italy pp 643644.

Romano A, Barros S, Martins-Loucao MA (2002). Micropropagation of the Mediterranean tree Ceratonia siliqua. Plant Cell Tissue Organ Culture 68:35-41.

Ruffoni B, Gazzano A, Costantino C (1994). Micropropagation of Myrtus communis Mill.: Effects of indolacetic acid on rooting. Italus Hortus 1:8-12 (in Italian).

Suttle GR (1999). Commercial laboratory production. In: Trigiano RN, Gray DJ (Eds). Plant Tissue Culture Concepts and Laboratory Exercises. CRC Press, Boca Raton, FL, USA pp 407-416.

Yeo DY, Reed BM (1995). Micropropagation of three Pyrus rootstocks. HortScience 30:620-623. 